
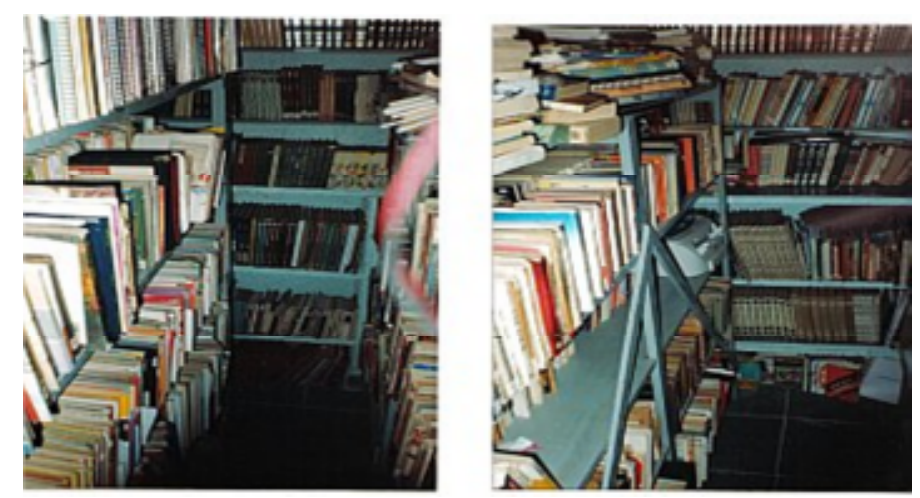

Fotos Lavínia Resende Passos

\title{
Bibliotecas Comunitárias: a tradição renovada do espaço de leitura
}

\author{
CACs Providência, Barreiro e São Paulo \\ por Jairo Rodrigues
}

Gislene Caldeira Brant e gerente do CAC Providência, Maria Aparecida Moraes e gerente do CAC Barreiro e Marta Soares é diretora do Centro de Convivência do CAC São Paulo.

Jairo Rodrigues é coordenador do Projeto Bibliotecas Autogeridas do Programa A tela e o texto

O acesso à leitura no Brasil é bastante prejudicado, seja pelos valores extremamente altos cobrados pelos livros, seja pela inexistência de bibliotecas próximas das comunidades, ou mesmo pela falta de programas eficazes de incentivo à leitura. No intuito de facilitar e promover o acesso à leitura nas regiões periféricas da Capital e da Região Metropolitana, o Programa de Ensino, Pesquisa e Extensão A tela e o texto iniciou, em janeiro de 2005, o Projeto Bibliotecas Comunitárias Auto-geridas, cujos objetivos são a criação e a manutenção de espaços de leitura que envolvam as comunidades nas quais estão ou serão inseridas. Nos casos em que já exista a biblioteca, o Programa atua de maneira a ampliar os números de visitação e empréstimos de livros. Em parceria com a Prefeitura de Belo Horizonte, através dos CACs - Centros de Apoio Comunitário -, o projeto inaugurou duas novas bibliotecas nas comunidades do Barreiro (em 18/08) e do bairro São Paulo (em 20/08). Além dessas duas bibliotecas, o Programa também está presente na biblioteca do CAC Providência, situado 
no bairro Minaslândia, onde são ministrados mensalmente cursos e oficinas que envolvam as questões da leitura. Para falarem um pouco sobre a experiência dessa parceria e seus desdobramentos, a Revista txt conversou com as Gerentes dos CACS Providência, Gislene Caldeira Brant, Barreiro, Maria Aparecida Moraes, e a Diretora do Centro de Convivência do CAC São Paulo, Marta Soares.

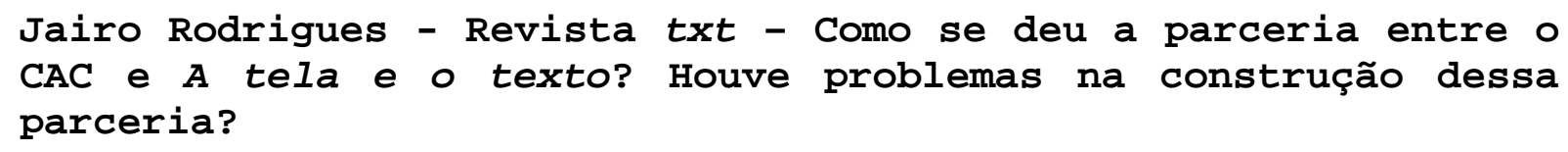

Gislene (CAC São Paulo) - A parceria deu-se inicialmente com o Centro de Convivência Saúde Mental, sendo o CAC posteriormente convidado a participar. Em seguida, após reunião com a coordenação d'A tela e o texto, o CAC assumiu o projeto. Com essa parceria, criamos o Projeto Lendo e Relendo que realiza atividades permanentes como oficinas de leitura, poesia e exibição de vídeos e filmes comentados. Para o CAC, foi importante essa parceria, pois conseguimos revitalizar a biblioteca através do Projeto Lendo e Relendo. Não tivemos problemas com a construção dessa parceria. Temos tido acompanhamento da coordenação de $A$ tela e o texto na elaboração da programação das atividades do Projeto Lendo e Relendo.

Marta (CAC Providência) - A parceria entre o CAC São Paulo e A tela e o texto ocorre através do Centro de Convivência que busca o contato na UFMG, na perspectiva de se ampliar o leque de opções para os usuários da saúde mental, com a oferta de atividades que integrem diferentes grupos, facilitando assim a aproximação entre portadores de sofrimento psíquico e sociedade.

Maria Aparecida (CAC Barreiro) - A parceria entre O CAC Barreiro e o Projeto A tela e o texto se deu com a mediação do Centro de Convivência Barreiro (Saúde Mental). À época, a gerente, Patrícia, participou de uma roda da área de saúde Mental, em que a professora Maria Antonieta, da UFMG e coordenadora do Projeto, colocou a experiência com o Centro de Convivência do CAC Providência. Em seguida, a discussão foi aberta no CAC Barreiro, para viabilizar a proposta com a nossa participação e a do Centro de Convivência Barreiro. A partir da oficina "Leituras da tela e do texto", no CAC ocorreram outros desdobramentos importantes: o planejamento da sala de Leitura (que inicialmente foi pensada como biblioteca) e que tem sido um projeto coletivo e bem partilhado, com a assessoria da UFMG e referências da comunidade (apoiadores) 
importantes; a biblioteca (com sua concepção técnica) será um próximo passo; a execução da proposta de alfabetização, com expectativa de inclusão digital, que está em curso; 0 desenvolvimento da oficina "Tecendo o Livro da Vida", com os grupos da terceira idade, foi outro importante momento criativo e alternativo do projeto. A construção da parceria foi bem debatida e bem acordada quanto aos papéis, às ações e aos acompanhamentos e apoio da UFMG.

\section{Txt - A criação ou a dinamização da biblioteca contribui para elevar os níveis de leitura da comunidade que freqüenta o CAC?}

CAC PROV - Sim. Hoje percebemos as pessoas passeando entre as estantes da biblioteca, escolhendo novas opções de leitura, sugerindo títulos e querendo participar das oficinas. É visível o aumento significativo do número de leitores e usuários.

CAC SP - A criação da Biblioteca Comunitária aumentou sim o nível de interesse pela leitura abrindo portas para o universo do conhecimento, que é algo de extrema importância, não só para aquela comunidade...

CAC Barreiro - A Sala de Leitura está iniciando seu processo de acolhimento da comunidade. O acesso à leitura está disponibilizado. Entretanto, por razões histórico-culturais a leitura ainda não seduz grande parcela da comunidade. Percebo que a experiência escolar de leitura obrigatória não causa grande prazer. Além disso, o cotidiano das famílias é preenchido pelo seu principal atrativo, a televisão (e para algumas outras, com maior poder aquisitivo, é o computador). Esses são fatores que vêm dificultando a elevação dos níveis de leitura na comunidade. Diante dessa preocupação, estamos pensando em projetos com usuários, com crianças, adolescentes (como visitas do nosso núcleo Infanto-Juvenil à sala de Leitura) e com a vizinhança, para elevar esses níveis. Pensamos em atividades de Contação de Histórias, Mala de Leitura e leituras na sala de espera do CAC e do Centro de Saúde Mental; além disso, o teatro e as artes plásticas motivados por novas oficinas de leitura, com a formação profissional (tivemos essa experiência recentemente com 0 grupo de formação profissional construindo algumas idéias e a convivência a partir do livro Nicolau teve uma idéia, de Ruth Rocha).

\section{Txt - Como a comunidade tem recebido a idéia da biblioteca comunitária?}


CAC SP - Para a comunidade que vive em torno, é a possibilidade de aproximação com o próprio CAC através da biblioteca. Internamente, ainda está em processo o envolvimento efetivo de todos os usuários dos programas ali existentes, com a idéia da biblioteca enquanto um lugar de todos, a ser construído por todos.

CAC Barreiro - A idéia tem sido recebida aos poucos, pelas razões já apontadas. O que precisamos é, então, criar soluções diferentes e sedutoras, para estabelecer o vínculo entre a comunidade e o desejo de ler.

\section{Txt - A comunidade envolveu-se com o projeto da biblioteca?}

CAC PROV - Sim. A comunidade e os alunos das escolas em torno do CAC têm demonstrado interesse em participar das atividades, percebe-se um envolvimento cada vez maior, com relação à leitura literária e à produção escrita. Em cada atividade a comunidade exprime seus saberes, percepções, interesses e recriações com base na leitura literária.

CAC SP - A comunidade interna, isto é, aquela que já freqüenta - CAC, só se envolveu de fato com o processo de criação da biblioteca num segundo momento, aliás, foi uma das experiências mais ricas ali vividas nos últimos tempos: a realização da Primeira Gincana Integrada que foi organizada em função da biblioteca. O Centro de Convivência teve uma participação diferenciada desde o começo, juntamente com 0 público

externo.

CAC Barreiro - A comunidade tem se envolvido, principalmente com a doação de livros e com os apoiadores voluntários para a organização e o funcionamento da sala de Leitura. o primeiro momento, articulado com a igreja local em dezembro de 2004, foi a entrega de livros literários no ritual do ofertório. Foi uma estratégia inédita, bem recebida, com o uso de oferenda diferenciada - e cerca de trinta livros foram doados.

\section{Txt - Pensa-se em expandir a atuação da biblioteca? Como?}

CAC PROV - Sim. Buscando novas parcerias e ampliando as atividades do Projeto Lendo e Relendo. Nossa proposta é a promoção da leitura dentro e fora da biblioteca. Essa parceria é um meio eficaz de continuarmos fazendo desabrochar leituras criativas e artísticas na comunidade. Queremos que o CAC seja um espaço novo e prazeroso de trabalho literário, viabilizando a integração com textos, situando a leitura e a literatura 
como opção de lazer, conhecimento, crescimento e questionamento.

CAC SP - Para o mês de outubro, já existe uma discussão sobre a criação de estratégias (como uma segunda gincana, por exemplo) para o desenvolvimento de um maior número de pessoas em torno da Biblioteca Comunitária. O projeto de expansão passa pela ampliação do espaço físico e pela aquisição de outros recursos como computador, DVD, mesas e cadeiras apropriadas. A idéia é envolver toda a comunidade.

CAC Barreiro - Sim. Primeiro, é preciso expandir a Sala de Leitura, depois consolidá-la como biblioteca propriamente dita. Esse passo tem que ser cuidadosamente planejado, começando pela visibilidade e pela identidade a serem conferidas à Sala de Leitura, construindo a participação cotidiana da comunidade. 